\title{
Sponsors' participation in conduct and reporting of industry trials: a descriptive study
}

\author{
Andreas Lundh ${ }^{1,2^{*}}$, Lasse T Krogsbøll ${ }^{1,2}$ and Peter C Gøtzsche ${ }^{1,2}$
}

\begin{abstract}
Background: Bias in industry-sponsored trials is common and the interpretation of the results can be particularly distorted in favour of the sponsor's product. We investigated sponsors' involvement in the conduct and reporting of industry-sponsored trials.

Methods: We included all industry-sponsored trials published in The Lancet in 2008 and 2009 and corresponding trial protocols provided by The Lancet. For each protocol and publication, we extracted information on trial conduct and reporting.

Results: We identified 169 publications of randomised trials and included 69 (41\%) that were industry-sponsored, and 12 (7\%) industry-funded but seemingly independently conducted as a subsample. Entry of data into the study database was done independently by academic authors without the involvement of the sponsor or a contract research organisation in one of the 69 trials. Two trials had independent data analysis and one independent reporting of results. In 11 of the trials, there was a discrepancy between the information in the protocols and papers concerning who analysed the data. In four of the 12 seemingly independent trials, the protocol described sponsors' involvement in writing the report while the published paper explicitly stated that the sponsor was not involved.

Conclusions: The sponsors are usually involved in the analysis and reporting of results in industry-sponsored trials, but their exact role is not always clear from the published papers. Journals should require more transparent reporting of the sponsors' role in crucial elements such as data processing, statistical analysis and writing of the manuscript and should consider requiring access to trial protocols, independent data analysis and submission of the raw data.
\end{abstract}

Keywords: Randomised trials, Industry sponsorship, Academic authors, Trial protocols

\section{Background}

The drug and device industries have a major impact on the research agenda. They funded $58 \%$ of US biomedical research in 2007 [1], and 56\% of trials published in highimpact medical journals in 2005 and 2006 had industry funding; for New England Journal of Medicine it was $78 \%$ [2]. The involvement of the company in industrysponsored trials varies from no involvement, besides the free provision of drugs, to running the whole trial and publishing the results without the involvement of academic authors.

\footnotetext{
* Correspondence: al@cochrane.dk

'The Nordic Cochrane Centre, Rigshospitalet, Dept. 7811, Blegdamsvej 9, DK-2100 Copenhagen, Denmark

${ }^{2}$ Institute of Medicine and Surgery, Faculty of Health Sciences, University of Copenhagen Blegdamsvej 3b, DK-2200 Copenhagen, Denmark
}

Industry-sponsored trials usually favour the company's product $[3,4]$. This may happen through biases in study design, choice of comparators or selective reporting of favourable outcomes $[5,6]$. Some journals therefore require that the involvement of the sponsor is stated in the published article. JAMA goes further and requires independent data analysis by academic authors [7].

Many industry-sponsored trials are coordinated by seemingly independent steering committees. However, this may not prevent sponsor influence, as academic authors often have constraints on publication rights $[8,9]$, the sponsor often owns the data $[9,10]$, ghost authorship is common [11], and academic authors may have industry ties [12].

\section{Biomed Central}


We have previously reported the results from a cohort of trials published in The Lancet in 2008 and 2009 [10]. We found that academic authors involved in industrysponsored trials may have limited access to the raw data, although they all declared in The Lancet that they had full access to the data. We report here on the sponsors' influence on trial conduct and reporting of the results.

\section{Methods}

\section{Sample}

We identified all randomised clinical trials published in The Lancet in 2008 and 2009 using the index term 'randomized controlled trial' in PubMed. We excluded papers that were not full trial reports (for example, letters and commentaries) or were not part of the planned trials (for example, secondary analyses). We selected all industry-sponsored trials, defined as trials fully funded by a drug or device company and where the sponsor participated in data management or analysis. Trials where part of trial conduct was outsourced to a contract research organization (CRO) were also included. Trials where all elements of trial conduct were managed by independent academic authors (for example, by 'unrestricted' grants) were analysed separately.

Since July 2002, The Lancet has required authors to submit protocols together with the trial report and we retrieved copies of these protocols.

\section{Information on trial conduct and reporting in protocols and papers}

One of us (AL) copied all information from protocols and papers on data management, storage, analysis, and writing of the protocol and manuscript into a pilot-tested data sheet. Two observers (AL, LTK) independently categorized these data into prespecified domains for protocols and papers, and disagreements were resolved by discussion and arbitration when needed by the third observer (PG). We made a final categorization based on data from both protocols and published papers and described discrepancies.

\section{Results}

We identified 209 papers in PubMed and excluded 40 that were not primary reports of trials published in 2008 and 2009 (Figure 1). We excluded another 85 trials that were not fully funded by the industry, two that had protocols similar to other included trials, and one that had no independent academic authors. Of the remaining 81 trials, we included 69 industry-sponsored trials. The other 12 trials were also fully industry-funded but appeared to have been independently conducted and we therefore analysed them separately.

For seven trials, the full protocols were missing: two were not in The Lancet's database, three were protocol synopses, one was a copy of the information from www.clinicaltrials. gov and one only consisted of amendments to the protocol.

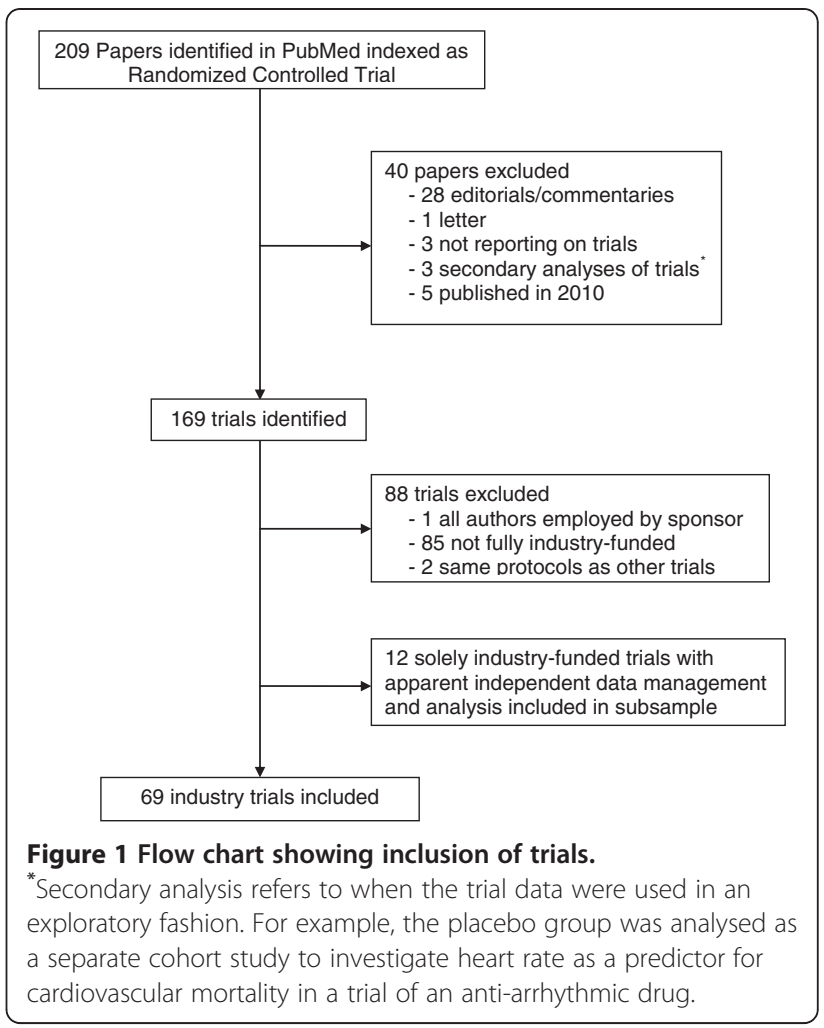

We received copies of five protocols from the academic authors and the other two from the sponsors.

\section{Data management}

In 49 of the 69 trials (71\%), review and verification of information in case report forms (CRFs) were handled by the sponsor or a CRO without involvement of academic authors and only in two trials (3\%) by academic authors independently (Table 1).

In 52 trials (75\%), entry of data into the study database was done by the sponsor or a CRO without involvement of academic authors. In only two of these trials, it was described how data were processed, that is, interpreted for categorisation purposes, and in those two trials, all safety data were processed by sponsor staff. In only one trial (1\%) was data entry performed independently by academic authors. However, based only on information in the published paper, it was not possible to tell who entered study data in $50(72 \%)$ of the trials. In 44 trials (64\%), the data were stored by the sponsor or a CRO and only in one trial (1\%) by academic authors. In one trial (1\%), the protocol suggested that academic authors stored the data whereas the paper suggested that the sponsor stored it.

According to 38 trial protocols (55\%), the sponsor had access to accumulating data before study termination and according to two (3\%) the sponsor had access via membership of the Data and Safety Monitoring Board. In 24 of these 40 trials, the sponsor could stop the trial prematurely 
Table 1 Data management and analysis in industry-sponsored trials based on information in protocols and publications

\begin{tabular}{|c|c|c|c|c|}
\hline$(n=69)$ & CRF review and verification & Data entry & Data storage & Data analysis \\
\hline Sponsor & $23(33 \%)$ & $32(46 \%)$ & $35(51 \%)$ & $29(42 \%)$ \\
\hline Sponsor and CRO & $18(26 \%)$ & $8(12 \%)$ & $3(4 \%)$ & $6(9 \%)$ \\
\hline CRO & $8(12 \%)$ & $12(17 \%)$ & $6(9 \%)$ & $5(7 \%)$ \\
\hline Sponsor/CRO and academic authors & $10(14 \%)$ & $0(0 \%)$ & $0(0 \%)$ & $11(16 \%)$ \\
\hline Academic authors & $2(3 \%)$ & $1(1 \%)$ & $1(1 \%)$ & $2(3 \%)$ \\
\hline Not described & $8(12 \%)$ & $16(23 \%)$ & $23(33 \%)$ & $5(7 \%)$ \\
\hline Discrepancy between protocol and paper & $0(0 \%)$ & $0(0 \%)$ & $1(1 \%)$ & $11(16 \%)$ \\
\hline
\end{tabular}

Percentages do not always add up to 100 due to rounding.

for a broad range of reasons or without any constraints at all, in five additional trials it could also be stopped but no criteria were specified, and in the remaining 11 trials it was not described whether the sponsor could stop the trial prematurely.

\section{Data analysis}

In 40 trials (58\%), the data were analysed by the sponsor or a CRO without involvement of academic authors and only in two trials (3\%) independently by academic authors. In 11 trials $(16 \%)$ the sponsor or a CRO, and academic authors analysed the data. However, in six of these trials, the sponsor or CRO biostatistician had the primary role and in five, the role was not clear as many authors were listed. In one of these five trials, the protocol named a sponsor-employed study biostatistician who was not mentioned in the paper.

In an additional 11 trials (16\%), there were discrepancies between information in protocols and papers. In four, the protocol described analysis by sponsor or CRO alone whereas the published paper described analysis either by academic authors alone or in collaboration with the sponsor. In five trials, there were discrepancies between information in protocols and papers as to whether the sponsor or a CRO did the analysis, and in two the protocol described an independent analysis by academic authors whereas the papers also described involvement of a CRO or the sponsor. Based only on information in the published paper, it was not possible to tell who analysed the data in another $10(14 \%)$ of the trials.

\section{Publication of the results}

In 24 of the 69 trials (35\%), the sponsor or a hired CRO was involved in coordinating writing of the manuscript, in 10 (14\%) the sponsor was not involved and in 35 (51\%) it was not described. In 64 trials (93\%), the sponsor had influence over publication of the results through co-authorship or an explicitly stated right to approve, review or comment on the paper (Table 2). In three trials (4\%), there were discrepancies between information in protocols and papers: one protocol described sponsor-employed co-authors without this being stated in the paper; in one protocol the sponsor needed to approve the manuscript, but the paper stated that the sponsor was not involved in writing of the report; and in one protocol the sponsor needed to approve the manuscript, but the paper stated that the report was written in consultation with the sponsor.

Ten of the protocols (14\%) referred to separate agreements (for example, clinical trial agreements or publication agreements) concerning reporting of results or data ownership and five other protocols (7\%) stated that such agreements might be issued, overriding statements concerning reporting of results or data ownership in the protocol. None of these agreements had been provided to The Lancet. Finally, five protocols explicitly described that the sponsor could publish the results without author approval, but this did not seem to have happened (there were academic authors on all 69 papers).

Medical writing assistance from the sponsor or persons hired by the sponsor was described in 37 of the 69 papers $(54 \%)$, in seven papers $(10 \%)$ it seemed no assistance was provided and in 25 (36\%) it was not described. Sixty-eight of the 69 protocols (99\%) seemed to have been written by the sponsor, for example, by including the company logo, and one protocol contained no information indicating who had written it. In 19 protocols, specific authors were named and 10 of these protocols specified them as authors of the protocol. However, for

\section{Table 2 Sponsors' influence on publication of results of industry-sponsored trials based on information in protocols and publications}

\begin{tabular}{lc}
\hline \multicolumn{1}{c}{$(\mathbf{n}=\mathbf{6 9 )}$} & Publication of results \\
\hline Sponsor has co-authorship & $56(81 \%)$ \\
Sponsor needs to approve manuscript & $3(4 \%)$ \\
Sponsor needs to review or comment & $5(7 \%)$ \\
No influence & $1(1 \%)$ \\
Not described & $1(1 \%)$ \\
Discrepancy between protocol and paper & $3(4 \%)$ \\
\hline
\end{tabular}

Percentages do not add up to 100 due to rounding. 
14 of these 19 protocols these authors were not mentioned in the publications.

\section{Independently conducted trials}

In eight of the additional 12 trials that appeared to have been conducted independently of the sponsor, the sponsor nevertheless appeared to have written the protocol, could stop the trial early, had issued confidentiality clauses or had influence on writing of the manuscript (Table 3).

\section{Discussion}

Approximately half the trials published in The Lancet were fully funded by the industry and most of these had industry involvement in the conduct, analysis and reporting of the results. The sponsor often entered, stored and owned the data, which were rarely analysed independently by the academic authors. Even for the additional 12 trials that appeared to have been conducted independently of the sponsor, the sponsor could stop the trial prematurely in some cases, issued confidentiality clauses, was involved in the reporting of results or appeared to have written the protocol.

Our study describes sponsor involvement in the conduct and reporting of industry-sponsored trials published in a high-impact medical journal. Our access to trial protocols gave us additional information on sponsor involvement not possible to decipher from the published papers alone. A study of cancer trials found that only $18 \%$ of the industrysponsored trials described the sponsors' role and usually in vague terms [13]. There are some limitations that should be taken into account though. First, we restricted our sample to trials published in a single journal, The Lancet, which may limit generalisability. However, The Lancet's access to protocols and editorial resources might indicate that the sponsors' role is greater for trials published in other journals. Second, despite access to trial protocols, in many cases we could not tell who entered, processed or stored data, and we did not have copies of trial agreements and publication agreements. We find it likely that tasks not described were handled by the sponsor because the protocols in all except one case were most likely written by the sponsor. It might therefore be regarded as implicit that what had been left out would be managed by the sponsor. The role of the sponsor may therefore be even more extensive than our results indicate.

Bias in industry-sponsored trials can be introduced at various levels of data processing, from the information being recorded on CRFs to the data appearing in the published paper. In most cases, the sponsor or a hired CRO was in charge of data entry and while it was rarely described, they probably also processed the data for categorisation purposes.

Processing data is bias-prone. Important data are often omitted from publications or are described in a way favourable for the sponsor. For example, suicidality was coded as 'emotional lability', 'hospital admission' or 'lack of effect' in trials of selective serotonin reuptake inhibitors (SSRIs) [14,15], myocardial infarctions on rofecoxib were omitted in the VIGOR trial $[16,17]$ and on rosiglitazone in the RECORD trial $[18,19]$. As academic authors were rarely involved in data entry, and as data analysis by academics often did not involve anything more than checking the tabulated data in the clinical study report [10], such practices will most likely not be discovered.

Academic authors were rarely involved in data analysis and only two trials had a completely independent analysis. When data analysis was performed jointly, the sponsor seemed to take the leading role and, for some trials, the role of academic authors in the actual statistical analysis was

Table 3 Eight seemingly independent trials with evidence of influence by sponsor

\begin{tabular}{|c|c|c|c|c|c|}
\hline \multirow{2}{*}{$\begin{array}{c}\text { Trial } \\
\text { number }\end{array}$} & \multirow{2}{*}{$\begin{array}{l}\text { Writing of } \\
\text { protocol }\end{array}$} & \multirow[t]{2}{*}{ Stopping trial early } & \multirow{2}{*}{$\begin{array}{c}\text { Author } \\
\text { confidentiality } \\
\text { clause }\end{array}$} & \multicolumn{2}{|c|}{ Writing of manuscript } \\
\hline & & & & According to protocol & According to publication \\
\hline 1 & - & - & In protocol & - & $\begin{array}{c}\text { Sponsor not } \\
\text { involved in writing }\end{array}$ \\
\hline 2 & - & - & - & $\begin{array}{l}\text { Sponsor needs } \\
\text { to review manuscript }\end{array}$ & $\begin{array}{l}\text { Sponsor not } \\
\text { involved in writing }\end{array}$ \\
\hline 3 & $\begin{array}{l}\text { Appears written } \\
\text { by sponsor }\end{array}$ & - & - & $\begin{array}{l}\text { Sponsor involved } \\
\text { in writing }\end{array}$ & $\begin{array}{c}\text { Sponsor not } \\
\text { involved in writing }\end{array}$ \\
\hline 4 & - & - & - & $\begin{array}{l}\text { Sponsor needs to } \\
\text { review manuscript }\end{array}$ & $\begin{array}{c}\text { Sponsor not } \\
\text { involved in writing }\end{array}$ \\
\hline 5 & - & $\begin{array}{c}\text { Sponsor must be consulted } \\
\text { before stopping }\end{array}$ & In protocol & $\begin{array}{l}\text { Sponsor needs } \\
\text { to approve manuscript }\end{array}$ & $\begin{array}{c}\text { Sponsor not } \\
\text { involved in writing }\end{array}$ \\
\hline 6 & - & - & - & $\begin{array}{l}\text { Sponsor needs } \\
\text { to review manuscript }\end{array}$ & $\begin{array}{l}\text { Nothing stated } \\
\text { about writing }\end{array}$ \\
\hline 7 & - & - & In protocol & - & $\begin{array}{c}\text { Sponsor not } \\
\text { involved in writing }\end{array}$ \\
\hline 8 & - & Sponsor can stop trial & - & $\begin{array}{l}\text { Sponsor allowed } \\
\text { comments }\end{array}$ & $\begin{array}{l}\text { Sponsor allowed } \\
\text { comments }\end{array}$ \\
\hline
\end{tabular}


probably limited, as many authors were named as contributors to data analysis. We find it highly unlikely that many academic authors with a clinical background actually participated in the statistical analysis, as such analyses are timeconsuming and require statistical expertise. Based on our previous study [10], such involvement might actually, again, be limited to merely reading the clinical study report.

Data analysis done solely by the sponsor is problematic, as independent analysis may yield different results [20]. In some cases, the data were analysed by CROs, but they are not independent. They are hired by the sponsor, they sometimes have financial interests in the sponsoring companies $[21,22]$, and - like for medical writers - if they do not do a job that satisfies the sponsors' marketing department, they might go out of business. Furthermore, analysis by academic authors does not ensure independence, as such authors often have financial ties to the industry [12]. Based on their declarations in the paper, in the two trials with independent analysis, the academic authors were paid by the companies for their contribution.

The sponsors' dominating role in data analysis is not only problematic in relation to selective reporting of positive outcomes and spin of the results [23,24], but also in relation to stopping trials early. If the sponsor has access to accumulating data, as was the case for at least 40 trials, and is allowed to terminate the trials prematurely, this could lead to overestimation of treatment effects [25] and underestimation of harms [26].

Journal editors should consider whether independent statistical analysis by academic authors should be a requirement, as is the case for JAMA [7]. This policy has had repercussions, as fewer industry-sponsored trials have been published [27]. Such policies might therefore be difficult to implement, as they will likely result in loss of revenue from reprint sales of industry trials [2]. However, this only reinforces the need for independent analyses. Lastly, journals should require copies of protocols and any additional agreements to ensure that access to the data was planned before the trial started. Journals should allocate editorial resources to ensure that what appears in publications corresponds to statements written in protocols, which was not always the case in our study. Such protocols should be written in accordance with evidence-based standards such as the upcoming SPIRIT guidelines [28] and should contain detailed information on authors' access to data. To ensure that such declarations are more than window dressing [10], journal editors might also consider asking for the raw data as a condition for publication, like Science and the $\mathrm{Na}$ ture journals require [23] and preferably make such data available at public websites.

\section{Conclusions}

The sponsors are usually involved in the analysis and reporting of the results in industry-sponsored trials, but their exact role is not always clear from the published papers. Even for fully industry-funded trials that appear to have been conducted independently, the sponsors are also sometimes explicitly involved in the reporting of results. Journals should require more transparent reporting of the sponsors' role in crucial elements such as data processing, statistical analysis and writing of the manuscript and should consider requiring access to trial protocols, independent data analysis and submission of the raw data.

\section{Competing interests}

The authors declare that they have no competing interests.

\section{Authors' contributions}

PCG conceived the idea for the study. The protocol was primarily developed by $A L$, and $L T K$ and PCG contributed. AL identified trials and protocols; $A L$ and LTK extracted data. All authors participated in data analysis and writing of the paper. AL, LTK and PCG are guarantors. All authors had full access to all the data in the study and take responsibility for the integrity of the data and the accuracy of the data analysis. All authors read and approved the final manuscript.

\section{Ethics}

The study was based on protocol data and published data and did not need ethical approval according to the Danish Act on a Biomedical Research Ethics Committee System and the Processing of Biomedical Research Projects.

\section{Funding source}

The study was partly funded by The Health Insurance Foundation and The Danish Council for Independent Research - Medical Sciences, partly by The Nordic Cochrane Centre.

\section{Role of sponsors}

The study was conducted independently of study sponsors. There was no sponsor involvement in the design; collection, analysis, and interpretation of the data; in writing of the report; or in the decision to submit for publication.

\section{Acknowledgements}

We thank the editors of The Lancet for providing us with copies of trial protocols. We thank the authors and companies for providing us with copies of the missing protocols.

Received: 18 January 2012 Accepted: 8 August 2012

Published: 24 August 2012

\section{References}

1. Dorsey ER, de Roulet J, Thompson JP, Reminick JI, Thai A, White-Stellato Z, Beck CA, George BP, Moses H 3rd: Funding of US biomedical research, 2003-2008. JAMA 2010, 303:137-143.

2. Lundh A, Barbateskovic M, Hróbjartsson A, Gøtzsche PC: Conflicts of interest at medical journals: the influence of industry-supported randomised trials on journal impact factors and revenue - cohort study. PLoS Med 2010, 7:e1000354.

3. Lexchin J, Bero LA, Djulbegovic B, Clark O: Pharmaceutical industry sponsorship and research outcome and quality: systematic review. BMJ 2003, 326:1167-1170.

4. Sismondo S: Pharmaceutical company funding and its consequences: a qualitative systematic review. Contemp Clin Trials 2008, 29:109-113.

5. Bero LA, Rennie D: Influences on the quality of published drug studies. Int J Technol Assess Health Care 1996, 12:209-237.

6. Dwan K, Altman DG, Arnaiz JA, Bloom J, Chan A-W, Cronin E, Decullier E, Easterbrook PJ, Von Elm E, Gamble C, Ghersi D, loannidis JP, Simes J, Williamson PR: Systematic review of the empirical evidence of study publication bias and outcome reporting bias. PLoS One 2008, 3:e3081.

7. DeAngelis CD, Fontanarosa PB: The importance of independent academic statistical analysis. Biostatistics 2010, 11:383-384. 
8. Schulman KA, Seils DM, Timbie JW, Sugarman J, Dame LA, Weinfurt KP, Mark DB, Califf RM: A national survey of provisions in clinical-trial agreements between medical schools and industry sponsors. N Engl J Med 2002, 347:1335-1341.

9. Gøtzsche PC, Hróbjartsson A, Johansen HK, Haahr MT, Altman DG, Chan AW: Constraints on publication rights in industry-initiated clinical trials. JAMA 2006, 295:1645-1646.

10. Lundh A, Krogsbø\|l LT, Gøtzsche PC: Access to data in industry-sponsored trials. Lancet 2011, 378:1995-1996.

11. Gøtzsche PC, Hróbjartsson A, Johansen HK, Haahr MT, Altman DG, Chan AW: Ghost authorship in industry-initiated randomised trials. PLoS Med 2007, 4:e19.

12. Rose SL, Krzyzanowska MK, Joffe S: Relationships between authorship contributions and authors' industry financial ties among oncology clinical trials. J Clin Oncol 2010, 28:1316-1321.

13. Tuech JJ, Moutel G, Pessaux P, Thoma V, Schraub S, Herve C: Disclosure of competing financial interests and role of sponsors in phase III cancer trials. Eur J Cancer 2005, 41:2237-2240.

14. Healy D: Let them eat Prozac. New York: New York University Press; 2004

15. Furukawa TA: All clinical trials must be reported in detail and made publicly available. BMJ 2004, 329:626.

16. Bombardier C, Laine L, Reicin A, Shapiro D, Burgos-Vargas R, Davis B, Day R, Ferraz MB, Hawkey CJ, Hochberg MC, Kvien TK, Schnitzer TJ, VIGOR Study Group: Comparison of upper gastrointestinal toxicity of rofecoxib and naproxen in patients with rheumatoid arthritis. N Engl J Med 2000, 343:1520-1528. 2 p following 1528.

17. Curfman GD, Morrissey S, Drazen JM: Expression of concern: Bombardier et al., "Comparison of upper gastrointestinal toxicity of rofecoxib and naproxen in patients with rheumatoid arthritis," N Engl J Med 2000; 343: 1520-8. N Engl J Med 2005, 353:2813-2814.

18. Psaty BM, Prentice RL: Minimizing bias in randomized trials: the importance of blinding. JAMA 2010, 304:793-794.

19. FDA Briefing Document. Advisory Committee Meeting for NDA 21071 Avandia (rosiglitazone maleate) tablet, July 13 and 14, 2010. [http://www.fda.gov/ downloads/AdvisoryCommittees/CommitteesMeetingMaterials/Drugs/ EndocrinologicandMetabolicDrugsAdvisoryCommittee/UCM218493.pdf]

20. Psaty BM, Kronmal RA: Reporting mortality findings in trials of rofecoxib for Alzheimer disease or cognitive impairment: a case study based on documents from rofecoxib litigation. JAMA 2008, 299:1813-1817.

21. Herper M: Money, math and medicine. Forbes Magazine 2010, [http:// www.forbes.com/forbes/2010/1122/private-companies-10-quintiles-dennisgillings-money-medicine.html]

22. Sismondo S: How pharmaceutical industry funding affects trial outcomes: causal structures and responses. Soc Sci Med 2008, 66:1909-1914.

23. Gøtzsche PC: Why we need easy access to all data from all clinical trials and how to accomplish it. Trials 2011, 12:249.

24. McGauran N, Wieseler B, Kreis J, Schüler Y-B, Kölsch H, Kaiser T: Reporting bias in medical research - a narrative review. Trials 2010, 11:37.

25. Bassler D, Briel M, Montori VM, Lane M, Glasziou P, Zhou Q, Heels-Ansdell D, Walter SD, Guyatt GH, STOPIT-2 Study Group, Flynn DN, Elamin MB, Murad MH, Abu Elnour NO, Lampropulos JF, Sood A, Mullan RJ, Erwin PJ, Bankhead CR, Perera R, Ruiz Culebro C, You JJ, Mulla SM, Kaur J, Nerenberg KA, Schünemann H, Cook DJ, Lutz K, Ribic CM, Vale N, et al: Stopping randomized trials early for benefit and estimation of treatment effects: systematic review and meta-regression analysis. JAMA 2010, 303:1180-1187.

26. Trotta F, Apolone G, Garattini S, Tafuri G: Stopping a trial early in oncology: for patients or for industry? Ann Oncol 2008, 19:1347-1353.

27. Wager $E$, Mhaskar R, Warburton S, Djulbegovic B: JAMA published fewer industry-funded studies after introducing a requirement for independent statistical analysis. PLoS One 2010, 5:e13591.

28. Strengthening the credibility of clinical research. Lancet 2010, 375:1225.

doi:10.1186/1745-6215-13-146

Cite this article as: Lundh et al:: Sponsors' participation in conduct and reporting of industry trials: a descriptive study. Trials 2012 13:146.

\section{Submit your next manuscript to BioMed Central and take full advantage of:}

- Convenient online submission

- Thorough peer review

- No space constraints or color figure charges

- Immediate publication on acceptance

- Inclusion in PubMed, CAS, Scopus and Google Scholar

- Research which is freely available for redistribution

Submit your manuscript at www.biomedcentral.com/submit 